J. Lake Sci. (湖泊科学), 2012, 24(2):320-326

http: //www.jlakes.org. E-mail : jlakes@niglas.ac.cn

(C) 2012 by Journal of Lake Sciences

\title{
禹䓠泽一一古黄河的一块天然滞洪区
}

王德甫 ${ }^{1}$, 王 超 ${ }^{2 * *}$, 王朝栋 ${ }^{3}$, 郭仰山 ${ }^{2}$

(1: 黄河水利委员会信息中心, 郑州 450004)

(2:河南省科学院地理研究所, 郑州 400052)

(3: 河南省地质勘查研究院,郑州 450000$)$

摘 要: 䓠泽是我国古代的一个著名湖泊, 是我国经典地理著作《禹贡》记载的湖泊之一, 其产生年代、形成环境及地理位 置一直存在着不同的认识. 本文以文献记载为线索, 通过野外实地调查, 从地质构造、地层分布和古地理环境诸方面, 对 䓠阳地区槽状洼地内的湖相地层进行了较为系统的研究, 并根据该地层的 ${ }^{14} \mathrm{C}$ 测年数据, 认为这一湖相地层是由《禹贡》 济水 “人于河, 溢为䓠” 的古湖泊所形成, 因此将这个古湖泊称作禹䓠泽. 这个古湖泊实际上相当于当时黄河的一块天然 滞洪区.

关键词: 禹䓠泽; 湖相地层; 天然滞洪区; 《禹贡》

\section{Lake Yuxingze, a natural flood detention area of the Yellow River in ancient time}

\author{
WANG Defu ${ }^{1}$, WANG $\mathrm{Chao}^{2}$, WANG Chaodong ${ }^{3} \&$ GUO Yangshan ${ }^{2}$ \\ (1: Center of Information, Yellow River Conservancy Commission, Zhengzhou 450004, P. R. China) \\ (2: Institute of Geographical Sciences, Henan Academy of Sciences, Zhengzhou 400052, P. R. China) \\ (3: Institute of Geology Exploration of Henan Province, Zhengzhou 450000, P. R. China)
}

\begin{abstract}
Lake Yuxingze is a famous ancient lake in China because it was recorded in a Chinese classic geography book of The Tribute of Yu (Yugong) and there have been some different opinions about its location, age and forming conditions. Based on the documentary records and field investigations, we study systematically the lake-appearance stratum in the trough wash of Xingyang region, including the geological conformation, the distribution of stratum and the ancient geographical surroundings. Especially according to the data of measured ${ }^{14} \mathrm{C}$ age, we think that this lake-appearance stratum had been made from the ancient lake described in The Tribute of Yu (Yugong) saying that the Jishui River flowed into the Yellow River but when it flooded, the name of this area was Xing, so we call this ancient lake the Lake Yuxingze. This ancient lake functioned actually as a natural flood detention area of the Yellow River then.
\end{abstract}

Keywords: Lake Yuxingze; the lake-appearance stratum; natural flood detention area; the Tribute of Yu (Yugong)

䓠泽是《禹贡》记载的湖泊之一, 隋文帝时又曾设立过一个䓠泽县, 尽管它早在三千年前已经因干涸而 消失, 还是不断引起人们的关注, 在一些历史文献中常常提到 “䓠泽”. 有文献认为它位于古䓠阳城 (现在的 古䓠镇) 之南, 也有文献认为它位于古䓠镇的东北或者其他地方. 《禹贡》虽是一部经典地理著作, 但毕竟总 共只有一千多言, 涉及䓠泽的文字也主要是 “导流水, 东流为济, 人于河, 溢为䓠”十三字. 《禹贡》之后的文 献对䓠泽的记述又多为只言片语, 因此对䓠泽的认识一直存在很大争议. 近些年在䓠阳地区发现与发掘了 数十座仰韶、龙山和夏商周三代的文化遗址, 很明显, 搞清䓠泽的产生与存在环境, 特别是数千年来其分布 范围与地理位置的变迁, 对研究这些文化遗址具有重要的现实意义. 鉴于此, 几年来作者在这里开展以实地 调查与取样分析为主的古环境研究工作, 以期对䓠泽获得一个深人与客观的认识.

* 郑州地区晚更新世以来古环境序列重建与人文聚落变化的预研究项目资助. $2010-12-13$ 收稿;2011-07-02 收 修改稿. 王德甫,男, 1940 年生,教授; E-mail: wangdefu@ gmail. com.

** 通信作者; E-mail : wangchao1966@ yahoo. com. cn. 
在郑州市西北部, 北起邙山, 西到汜水一官庄峪黄土岭, 南到嵩山余脉的丘陵岗地, 东到师家河黄土陡坎 以东(图 1), 本文称作䓠阳地区, 该地区内有一由东西向的槽状洼地, 地表之下约 $1 \mathrm{~m}$, 普遍存在一层大致 $1 \sim 2 \mathrm{~m}$ 厚的湖相沉积地层, 说明古代这里曾经存在过一个湖泊. 根据有关文献记载的提示, 对这里的古地理 环境进行调查研究, 结果表明形成湖相地层的湖泊就是《禹贡》中所记载的塚泽. 因此, 称其为 “禹䓠泽”, 并 曾将这一认识写成一篇短文报导于《地域研究与开发》2010 年第一期. 但是, 由于篇幅的限制, 无论是对古 地理环境的论述, 还是对历史文献的分析都不充分, 特别是当时缺乏对湖相地层的具体观测和测年数据. 我 们深知, 若想将数千年前已经消失的古湖泊搞清楚, 使调查研究成果能够有效地应用于考古调查与研究还 有许多工作要做. 鉴于此, 作者对那篇短文进行了补充和较大的调整, 增加了近一年多以来调查研究的新成 果, 以便更好地开展今后的环境考古工作.

$113^{\circ} 10^{\prime} \mathrm{E}$

$113^{\circ} 36^{\prime} \mathrm{E}$

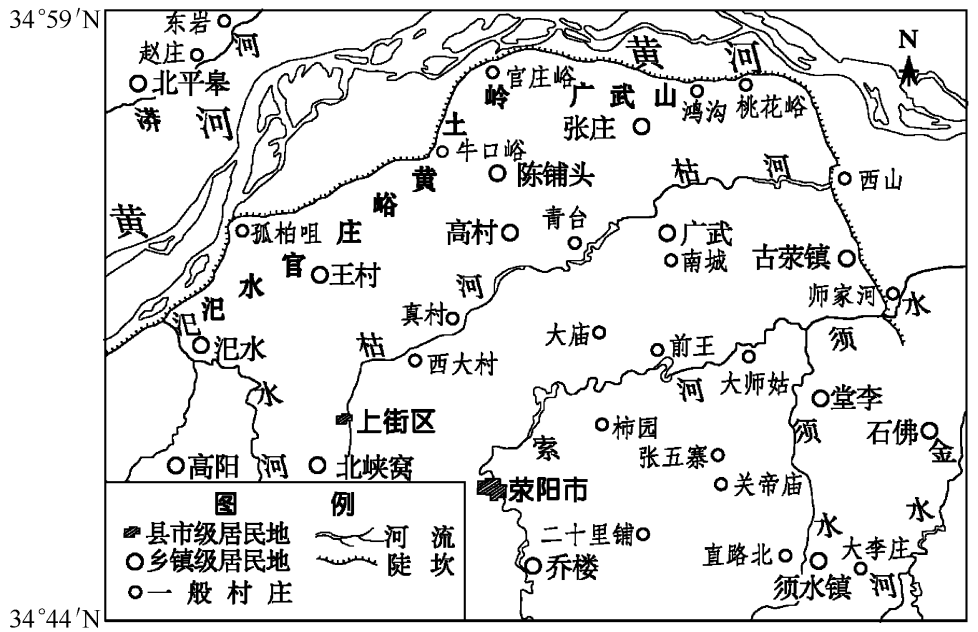

图 1 䓠阳地区地理示意图

Fig. 1 The geographical sketch map of Xingyang region

\section{1 䓠阳地区全新统湖相地层}

用地质学的方法对一个地区的古地理环境进行考察, 主要是通过对调查区出露地层的“岩相” 分析实现 的. 依据地质学中沉积岩石学原理, 地球岩石圈中的沉积岩 (包括部分松散堆积), 都是各种原岩 (岩浆岩、变 质岩和沉积岩) 在不同营力作用下, 遭受侵蚀、搬运和堆积形成的. 由于侵蚀、搬运和堆积过程不同, 所形成 的堆积物相应地具有不同的特征和性质. 这在地层学中被称作 “岩相”. 由此, 反过来通过 “岩相” 分析, 则可 以判断堆积物形成时候的自然地理环境. 湖泊里的沉积叫 “湖相”堆积. “湖相”地层的有无可以确定一个地 区是否有古湖泊存在. 䓠阳地区槽状洼地基本上是晚更新世以来的继承性洼地, 在这个洼地内于全新世早、 中期沉积了一套湖相地层.

\section{1 湖相地层剖面}

曾有人将作者认为属于湖相的地层当作古土壤. 因为, 在古土壤剖面中也有厚厚的 “粘化层” 存在. 其 实, 二者在成因和地层结构方面都有本质差别. 这些差别首先在于湖积地层的物质是外来的. 䓠阳地区湖积 地层的组成物质, 来源于黄河洪水和周围地表径流携带的悬浮碎屑. 这些悬浮碎屑粒径微小, 一般在 $0.02 \sim$ $0.002 \mathrm{~mm}$ 之间, 称为粉砂和粘粒, 形成的地层主要是亚砂土、亚粘土和粘土. 古土壤则是在陆地条件下, 由当 地的成土母质在特定气候、生物和地貌条件下, 经历长期成土化过程逐渐形成的, 它的物质来源在本地; 其 次, 湖积地层受来水条件及其携带物质变化的影响, 其沉积一般层次分明. 大庙村附近湖相地层剖面中的第 4 层仅 $30 \mathrm{~cm}$ 厚, 其中却清晰地夹有两层 $2 \sim 4 \mathrm{~cm}$ 厚的不同沉积. 而古土壤是在陆地条件下形成的, 它也有 一定层次, 层与层之间却是渐变的. 湖积地层与古土壤的层次结构具有明显差异. 因此, 䓠阳地区湖积地层 
和古湖泊的存在是客观现实. 张五寨和大庙村附近湖相地层的实测剖面见表 1 .

表 1 张五寨和大庙村附近湖相地层的实测剖面

Tab. 1 Profiles of lake-appearance stratum in the vicinity of Zhangwuzhai and Damiao

\begin{tabular}{lcccll}
\hline & 地质时代 & 累积厚度 $/ \mathrm{m}$ & 层厚/m & 层序 & 岩性特征 \\
\hline 张五寨 & 全新统 Q4 & 0.8 & 0.8 & 1 & 粉土,灰黄色 \\
& & 1.2 & 0.4 & 2 & 粘土,棕褐色 \\
& 2.4 & 1.2 & 3 & 亚粘土、粘土,灰褐色、灰色、黑灰色,下为钙质粘土 \\
& & 2.8 & 0.4 & 4 & 粘土,含铁锈黄色斑块 \\
& & 0.2 & 0.2 & 1 & 表层(耕植土壤) \\
& 1.0 & 0.8 & 2 & 灰黄色,粉砂土 \\
& 1.6 & 0.6 & 3 & 褐灰色,粘土 \\
& 1.9 & 0.3 & 4 & 灰黄色,亚粘土,夹两层蝎色粘土 \\
& 2.6 & 0.7 & 5 & 褐灰色,粘土 \\
& 3.7 & 1.1 & 6 & 灰色粘土,含有灰黄色泥栋,未见底 \\
\hline
\end{tabular}

\section{2 湖相地层分布范围}

根据野外调查,这组湖积地层的分布范围, 基本与䓠阳地区槽状洼地的范围一致, 北缘大致起自邙山 ( 又 叫广武山) 南坡坡脚, 西界在汜水一官庄峪黄土岭以东, 南缘到须水镇一䓠阳市一线, 东到师家河黄土陡坎以东, 面积在 $250 \mathrm{~km}^{2}$ 以上. 这肯定不是一个确切的范围, 因为据现在估计, 禹䓠泽前后存在了四、五千年, 期间随着 区域环境的变化不仅湖面大小有所变化,湖泊的中心位置肯定也会有所改变,上述面积是湖积地层的总面积.

\section{3 湖积地层的地质时代}

䓠阳地区这组湖相地层, 通常都夹在全新世地层中间, 或者直接覆盖在晚更新统地层之上, 因此判断它 的地质时代应为中、早全新世. 刘钧枢在《郑州全新世地层初探》 ${ }^{[2]}$ 中指出, 直路北村 $\left(34^{\circ} 46^{\prime} \mathrm{N}, 113^{\circ} 30^{\prime} \mathrm{E}\right)$ 的 地层剖面中, 这层湖相亚粘土的 ${ }^{14} \mathrm{C}$ 年代测定为距今 $4135 \pm 120 \mathrm{aBP}$, 该年代处于夏禹时代内, 也与《禹贡》济 水“人于河,溢为䓠”年代记录相一致.

作者在野外调查中, 分别对张五寨北 ( $34^{\circ} 48^{\prime} \mathrm{N}, 113^{\circ} 28^{\prime} \mathrm{E}$ )、司马村北 $\left(34^{\circ} 53^{\prime} \mathrm{N}, 113^{\circ} 20^{\prime} \mathrm{E}\right.$ )、后真村西 $\left(34^{\circ} 52^{\prime} \mathrm{N}, 113^{\circ} 20^{\prime} \mathrm{E}\right)$ 三个剖面点湖积层中有机粘土取样测定 AMS $-{ }^{14} \mathrm{C}$, 三个剖面点的深度分别为 $160 、 220$ 、 $130 \mathrm{~cm}$, 测定结果表明, 其年代分别为 $5625 \pm 29 、 6108 \pm 24 、 7411 \pm 30 \mathrm{aBP}$ ( 中国科学院广州地球化学研究所 测定). 这些结果与文献记录相当吻合, 反映出禹䓠泽在夏禹之前已经存在. 因此, 本文推断, 该湖积层应当 产生于全新世的中、早期,也就是说禹䓠泽存在的时间大致距今 8000 ～3000 a.

\section{2 禹䓠泽的成湖环境}

\section{1 地貌条件}

2.1.1 现代地貌 在古䓠泽存在过的这块地方, 现在仍然是块低洼地, 北边是邙山. 虽然被称作山, 实际上属 于黄土丘陵,呈东西向分布,海拔高一般在 $200 \sim 250 \mathrm{~m}$ 之间, 个别高点达 $260 \mathrm{~m}$. 邙山北坡面临黄河,坡陡、 多冲沟, 冲沟呈南北向,南高北低,沟长一般 $1000 \sim 1500 \mathrm{~m}$. 鸿沟是其中之一. 鸿沟又叫广武涧, 丰水年份的 夏秋季节有溪水自南而北注人黄河. 邙山的南坡坡度平缓,高度下降到索河附近地势最低,再向南地势又逐 渐升高,一直到进人南部山地丘陵区. 因此, 这里便形成了南北高、中间低, 呈东西向延伸的槽状地带. 槽状 地带西端高、东边低. 西端从汜水到官庄峪有一带状黄土低丘陵,一般海拔高 $140 \sim 220 \mathrm{~m}$. 这一黄土岭西北 坡陡,紧邻黄河, 东南坡缓, 和亡山一样,也已被大小冲沟切割得支离破碎. 这块低洼地带的东沿, 即京广铁 路的西侧, 有一个高差 $10 \sim 15 \mathrm{~m}$ 的黄土陡坎, 作者将其称为师家河黄土陡坎. 陡坎西高东低, 构成了豫西山 地丘陵区与豫东大平原的分界.

2.1 .2 古代地貌 在四、五千年前,这里的地貌形态与现在差别不大,差别主要表现在地势高低变化上. 䓠阳 地区的槽状洼地具有继承性, 晚更新世就曽存在过大李湖. 禹䓠泽仍然存在于这个槽状洼地内. 那时候䓠阳 地区的地势和黄河相比要低 $25 \sim 30 \mathrm{~m}$. 部山与黄河的高差比现在小, 当时禹䓠泽的东沿还不存在现在那道 
陡坎. 槽状洼地东部与平原不存在明显高差.

\section{2 地质环境}

出露于䓠阳地区的地层主要是新生界地层, 但上、下第三系和下更新统地层很少, 中更新统离石黄土、 上更新统马兰黄土和黄土类土却分布广泛. 禹䓠泽的湖积物除主要来源于黄河洪水携带的泥砂外, 也来源 于当时周围地表径流携带的黄土风化物. 对研究禹䓠泽古地理环境具有重要价值的地层是: (1) 鸿沟洪积层, 这是一组薄层状浅灰黄色亚粘土, 仅见于黄河南岸黄土冲沟两侧的上部, 通过对其分布位置、成份、结构、成 岩程度和存在高度分析, 只有一种解释, 它们是黄河阶地后缘低洼地带的静水沉积, 是由黄河洪水形成的. (2) 洛口冲积层, 是一组存在于黄河南岸伊洛河口下游洛口村沟中的一组砂砾石层, 组成物质为浅黄色、淡黄 绿色粗砂、中砂和粉砂土,其成份表明物质主要来自沟谷的上源——南边的山地丘陵区.

鸿沟洪积层的存在具有两种指示性意义: (1) 鸿沟洪积层的高度,按照其顶板计算, 当时黄河水面的海拔 高度相对于䢵山至少要高 $25 \sim 30 \mathrm{~m}$; (2) 当时的黄河流路靠近䢵山, 黄河流路的靠近为济水 “人于河, 溢为 䓠”提供了条件.

洛口冲积层存在的佐证作用. (1) 和鸿沟洪积层一样, 当时的黄河逼近洛口沟沟口, 只有这样它对来自洛 口沟上源的流水才有阻滞和顶托作用. 没有阻滞和顶托作用, 就不能形成洛口冲积层; (2) 由分布高度判断, 洛口冲积层产生的时代与鸿沟洪积层相同.

鸿沟洪积层和洛口冲积层的存在说明, 当时的黄河水位相对于邙山要高 $25 \sim 30 \mathrm{~m}$, 使得黄河洪水能够 顺利地从汜水一官庄峪黄土岭低洼处溢人䓠阳地区槽状洼地中.

\section{3 区域地质构造}

2.3.1 区域构造运动 有区域地质勘查报告指出: 在“晚更新世末期,新构造运动在区内表现为暂短时期的 上升,继而变为缓慢的间歇性下降” ${ }^{[3]}$ 正是在这一缓慢下降期间, 使䓠阳地区相对于黄河下降, 从而使黄河 洪水越过汜水一官庄峪黄土岭低洼处, 溢人䓠阳槽状洼地形成了《禹贡》记载的䓠泽. 而在全新世中期末, 该 勘查报告指出: “新构造运动从缓慢下降转为剧烈上升,并延续至今,上升幅度达 $20 \sim 40$ 余米”. 正是这次抬 升, 抬高了䓠阳地区相对于黄河的高度, 使得黄河洪水不再溢人䓠阳槽状洼地, 《禹贡》记载的䓠泽便失去了 重要水源.

2.3.2 断裂构造 有地质报告指出, 䓠阳地区存在几条对地形影响较大的断裂构造 ${ }^{[4]}$ : (1) 郑州一兰考断裂呈 东西向展布, 西起邙山南坡, 沿黄河南岸东到兰考. 正断层, 倾向南. 对形成槽状洼地北沿起着重要作用. (2) 乔楼-白沙断层 (须水断裂) 是一条继承性断裂, 呈东西向展布. 正断层,倾向北. 它对形成槽状洼地南沿 起着重要作用. (3) 郑州-武陟断裂 ${ }^{[5]}$ 呈西北东南向, 沿郑州一黄河之间的京广铁路线展布. 正断层, 倾向东北. 地貌上表现为师家河黄土陡坎的形成.

\section{3 禹䓠泽的水文学特征}

\section{1 禹䓠泽的水文学环境}

黄河沿三门峡河谷东流, 于孟津附近流出豫西山地进人与华北大平原的接壤地带, 因此, 人们常常将孟 津视作黄河冲积扇的扇顶. 其实山经河、禹河或者此后黄河任何大的改道起始点都在温县河段下游, 因此实 质上的冲积扇扇顶也应当在温县河段以下. 这是因为黄河在温县河段的北岸有一东北一西南向的带状高地 清风岭, 清风岭与黄河对岸的汜水一官庄峪黄土岭为黄河形成一个通道, 在这个通道中黄河北岸虽然有宽阔 的温孟滩存在, 但这里的黄河与下游的黄河性质和地貌条件不同, 所以黄河水利委员会将黄河的中、下游分 界放在更下游一点的桃花峪. 黄河桃花峪以下河道两侧广泛分布着背河洼地, 背河洼地中形成的湖泊, 随河 道变迁而存废, 不可能形成《禹贡》记载那样的䓠泽. 䓠阳地区槽状洼地主要是由当地的地质构造活动造成 的, 虽然与黄河一岭之隔, 但不是背河洼地, 它所存在的时间可以用地质年代来度量, 也就是说它可以稳定 地存在相当长时间, 为禹䓠泽的产生与存在提供空间与时间.

\section{2 禹䓠泽的湖水来源}

禹䓠泽的湖水主要来源于黄河洪水,正像《禹贡》说的由济水 “人于河, 溢为䓠”而来. 当然, 济水既然注 人了黄河, 如果有洪水从对岸溢出, 只能算作黄河水, 这是不能再与《禹贡》作者计较. 正如目前被大家所熟 
知的,在距今 8000 3000 a 之间正是我国北方地区气候相对温暖、降雨丰沛时期,特别是夏禹生活年代的前 后更是如此, 洪水量大, 发生洪水的频度也高, 为禹䓠泽提供了丰富的水源. 禹䓠泽的湖水还来源于周围的 地表径流,特别是索河和须水河发源于南部山区, 渊远流长、积水面积大、流量大, 它们不仅为禹䓠泽提供了 大量地表径流, 而且在䓠阳地区地势抬升, 黄河洪水逐渐不再溢人时,这些地表径流的注人,使禹䓠泽又维 持了相当长的时间.

\section{3 禹䓠泽是黄河的一个天然滞洪区}

对于《禹贡》济水“人于河, 溢为䓠” 的记载, 后世文献曽经有过不少解释. 《水经注》引《晋地道志》曰: “济自大伾人河, 与河水斗, 南溢为䓠译”, 是比较典型者. 关于《水经注》, 本文采用杨守敬、熊会贞《水经注 疏》 ${ }^{[6]}$ 中的版本. 《禹贡》济水 “人于河, 溢为䓠” 反映了两方面的事实: 一是 “溢为䓠” 的水是从黄河溢出来 的,二是 “溢为䓠” 的水是 “洪水”. 这说明禹䓠泽实际上就是黄河的一个滞洪区. 在现代, 黄河下游设置了一 些滞洪区,如北金堤滞洪区、东平湖蓄滞洪区等, 以便需要时进行人工分洪,有控制地将洪水暂时排人,以避 免自然决溢造成巨大损失. 禹䓠泽这个滞洪区, 在黄河发生洪水时, 洪水将流人其中. 禹䓠泽范围巨大, 能够 蓄积巨量洪水. 不过禹䓠泽蓄积洪水只是一种自然现象, 那时, 先民们不懂、也没有力量、甚至没有必要用这 种方式对洪水进行人工干预.

\section{4 水阳地区槽状洼地中的古湖泊是《禹贡》记载的䓠泽}

《禹贡》之后历史文献记载的䓠泽,因文献不同其地理位置多有所不同,但这些文献都认为它们记载的 就是《禹贡》记载的䓠泽. 这给研究真正《禹贡》记载的䓠泽造成一定认识上的混乱. 本文将分别从地理位 置、水文学特征和存在年代三方面加以澄清.

\section{1 禹䓠泽与《禹贡》之后文献中䓠泽的地理位置}

1 ) 禹䓠泽的地理位置. 作者在前文已从地质、地理和水文环境方面论述了䓠阳地区槽状洼地中的古湖 泊是《禹贡》记载的䓠泽,这一结论也可从文献记载得到证实.

(1) 人们通常将凡是阳光照耀的地方称为阳. 以此,山南为阳,水南为阴, 反之亦然. 所以, 靠近水的地方 便出现了江阴、洛阳等地名. 在䓠泽之北筑城并称为䓠阳本是情理之中的事. 《嘉靖䓠阳县志》 ${ }^{[7]}$ 记载: “根据 《史记》、《战国策》等记载,䓠阳城之筑城时间,约在公元前三七五至公元前三一一年之间.《史记》记公元前 二四九年 “秦拔我䓠阳” 时, 䓠阳早有城池”. 《河南省地图集》 ${ }^{[8]}$ 记载: “以䓠为名, 始自《尚书. 禹贡》中的 “䓠波既潴”. 战国韩在䓠泽之北筑城, 名曰䓠阳 (即今郑州西北古䓠镇). 西汉置䓠阳县. 北魏太和十七年 (493 年) 徙治大栅城 (今䓠阳市区)”. 这些记载说明古时候的䓠阳城在䓠泽之北, 而古时候的䓠阳城恰恰位 于䓠阳地区槽状洼地的北缘. 那么,洼地内的湖泊就是䓠泽便不言而喻.

(2) 禹䓠泽的地理位置还可用《禹贡》、《水经注》等重要文献记载来判定.《禹贡》记载: “导流水,东流为 济, 人于河,溢为䓠”. 我们不认同济水 “人于河”之后, 由黄河对岸溢出的洪水仍是济水. 但是, 它所描述的 “人于河, 溢为䓠” 过程, 却反映一个明确概念, 就是 “溢为䓠” 处一定与济水 “人于河” 处相距不远. 《水经注》 河水部分曰: “济水故道之所人,与成臬分河”. 杨守敬《水经注疏》按: “平臬在河北,成臬在河南, 二县以河 为界, 故云分河” 说明济水人河处与溢出口直接相对. 《水经注》河水部分又说: “河水又东, 迳成臬大伾山 下, ……沇出伾际, …‥伾北即《经》所谓济水从北来注之者也. 不于此也, 所人者奉沟水耳, 即济治之故渎”. 意思是, 济水故渎由大伾山对岸人河. 奉沟水就是济水故渎. 大伾山在汜水-官庄峪黄土岭西端.《水经注》济 水部分说: “《释名》曰, “济,济也. 源出河北,济河而南也””. 所有这些记载对“人于河,溢为䓠”的解释都说 明,济水人河之地与溢䓠之地是隔河相对的. 当然也有反对洪水由这里 “溢为䓠” 的, 傅泽洪在《行水金 鉴》 ${ }^{[9]}$ 中说: “故济水自人河以至于溢䓠, 用后世郡县言之,则其人河在温, 温与巩对. 而溢䓠之地, 决不在巩 与成臬也. 盖巩有洛, 成臬有汜, 二水皆反来注河, 以其特高故也”. 其实,这句话的第一部分正好与我们的认 识一致,即“人于河, 溢为䓠” 的过程均发生在同一地方的黄河两岸. 而这句话的后半部分, 仅仅是因为四、五 千年前䓠阳地区的地势相对于黄河并没有现在这么高. 总之, 黄河自孟津东下, 到达汜水一官庄峪黄土岭时， 洪水越过黄土岭东流才是《禹贡》所指的溢䓠之地.

2)《禹贡》之后文献中䓠泽的地理位置.《禹贡》之后文献中䓠泽的地理位置随文献不同而不同,仅选几 
个例子加以说明：

(1) 《左传・闵公二年》记载 ${ }^{[10]}$ “冬十二月, 狄人伐卫, 卫懿公好鹤, 将战, $\cdots \cdots$ 及狄人, 战于䓠泽, 卫师败 绩, 遂灭卫”. 《左传》中䓠泽的位置应根据狄人伐卫的情节进行判断. 狄人伐卫的时候, 黄河自北平臬与官庄 峪之间流向东北, 沿武陟东南、获嘉东南、新乡南郊流向浚县和淇县. 淇县是卫国的首都朝歌. 不夺取朝歌, 何以灭卫,所以《左传》中的䓠泽, 在新乡附近或者以北.

(2) 胡渭在《禹贡雉指》 ${ }^{[11]}$ 中提到 “传云: 济水人河, 并流数十里, 而南截河, 又并流数里溢为䓠泽, 在敖仓 东南”. 很明显, “敖仓东南” 指的就是后来隋朝设置䓠泽县的地方. 䓠泽县位于现在的古䓠镇东北十七里. 这 个䓠泽应是客观存在的, 否则后来也不会在那里设置一个䓠泽县. 问题是这个䓠泽不是《禹贡》记载的䓠泽. 胡渭说 “大伾山在汇水县西一里, 济自大伾人河之河阴县四十一里, 又东十余里, 通计五十余里”. 他这样将 济水“人河之地” 和“敖仓东南” 的䓠泽联系起来, 不符合数千年前《禹贡》作者“人于河, 溢为䓠” 的原意.

(3) 2007 年 9 月, 《陕西师范大学继续教育学报》刊登了一篇名为 “古䓠泽考” ${ }^{[12]}$ 的文章. 作者认为 “若以 现在的地理方位来看, 䓠泽位置应在今广武山、大伾山以北, 黄河北岸御坝、秦厂、老田庵、大茶堡一线黄河 大堤之南的区域之内求之”. 胡渭说: “大伾山在汜水县西一里” ${ }^{[11]}$, 大伾山以北处于清风岭与汜水-官庄峪 黄土岭夹道内, 没有足够的地理空间和适宜的地貌条件形成《禹贡》记载的䓠泽. 御坝、秦厂和大茶堡距老田 庵都只有四、五公里, 老田庵位于原郑州黄河铁桥北端, 那里正是古䓠镇东北十七里附近. 这里曾经有过一 个塚泽,应是上述“敖仓东南”的那个䓠泽.

\section{2 《禹贡》之后文献中䓠泽的水文学特征}

《禹贡》之后文献中有一些曾涉及䓠泽水文学特征的记载,这里也举几个例子:

(1)《水经注》不仅记载了禹䓠泽的相关信息, 同时在卷七济水部分也记载了另一个形成于东汉初年的 䓠泽: “济水又东, 迳敖山北. 济水又东, 合䓠渎, 渎首受河水, 有石门, 谓之为䓠口石门也, 而地形殊卑, 蓋故 䓠播所道, 自此始也”.《水经注》接着引阚骃曰: “䓠播, 泽名也”. 所以䓠播就是䓠泽. 引文中的济水即是所 谓的“出河之济”, 实际上是黄河的一条汉流, 它经敖山北麓东流, 这时的黄河干流当然在北面, 济水东流的 时候遇到了来自黄河干流的䓠渎(另外的一条汉流), 因为二者交汇的地方地势特别低洼就形成了䓠泽. 考 其地理位置,应是上述“敖仓东南”那个䓠泽,其形成环境为黄河的背河洼地.

(2) 杜省吾在《黄河历史述实》 ${ }^{[13]}$ 中提到 : “黄河在秦始皇时期化零为整之前, 局部堤防主要保障城市不 被洪水淹没, 田野免不了有洪水泛滥之灾”. 在当时情况下, “黄河河道地势不像后代如此高仰. 而是广漙平 衍, 出为诸泽, 如戋田、孟诸等泽”. “黄河与渠、泣之间, 有广阔之泽, 为洪水猥盛放溢之所”. 所以他指出: “黄河出孟津已达平原, 逾亡山 (郑州市北) 而汇成巨浸,南北两岸俱称䓠泽”.

(3) 1980s 有篇文章提到䓠泽时说: “䓠泽有多大? 据《水经注》记载, 水泽在古䓠阳城之东, 管城之西, 是 个不大的湖泊. 但初塞淫水形成的䓠泽, 其大当不止此. 䓠泽南有㚘城陂, 东西四十里, 南北二十里.《水经. 济水注》引: ‘竹书, 穆天子传曰, 甲寅, 天子浮于䓠水, 乃奏广乐是也’ 称㚘城陂为䓠泽, 故知㚘城陂亦䓠泽, 除㚘城陂外, 䓠泽当更包括戋田泽” ${ }^{[14]}$.

(4) 岑仲勉在《黄河变迁史》 ${ }^{[15]}$ 中是这样认识䓠泽的: “按明人刘天和《问水集》称, “孟津而下, 夏秋水 涨, 河流甚广, 䓠泽 (县) 漫溢至二三十里 ’ 明代尚这样宽阔, 则在千余年前, 春秋之末, 河面必更汪洋可观. 换句话说, 河水流至䓠泽县地面, 一望无际, 就好像汇成一个大湖, “溢为䓠”这句, 也许是古人对于河流宽广 的简描, 所以,南北两岸都可以称为䓠泽. 有此进一步的了解, 我们直可不必追问古代有无 “䓠泽” ”.

上述几位作者中, 畉道元记载的《水经注》中形成于两条汉流交汇处的䓠泽, 位于黄河背河洼地中;一位 认为䓠泽应当包括戋田泽; 另两位实际上是在论述黄河的洪水现象, “直可不必追问古代有无䓠泽”.

\section{3 关于《禹贡》之后文献中䓠泽的存在年代}

《禹贡》之后涉及䓠泽的历史文献中, 可以推断相关年代信息的有下列几个例子:

(1) 本文上述例子中, 《水经注》记载的由济水在低洼处与䓠渎交汇形成的䓠泽, 由于䓠渎来自䓠口石 门, 而䓠口石门修建于东汉, 显然这个䓠泽产生于东汉. 但是, 䓠口石门修建之前不排除有自然口门存在, 那 么,这个䓠泽也可能产生得更早一些.

(2) 前面举过《左传 - 闵公二年》的例子, 这个例子说狄、卫曾战于䓠泽, 那么, 起码说明狄、卫打仗之前 
䓠泽已经存在, 至于什么时间消失, 《左传》没有说. 然而,《行水金鉴》中却有这样一段话: “䓠泽者, 禹时济 溢, 为䓠水所注射, 潴为此泽也. 春秋卫侯及翟人战于䓠泽, 此时泽枯无水, 至可以战, 民犹谓其处为䓠泽 也”. 它的意思是: 卫侯及翟人战于䓠泽, 是因为卫、狄打仗的时候䓠泽已经干枯, “至可以战”. 那么, 这个䓠 泽应当是在闵公二年(公元前 661 至公元前 660 年) 之前消亡的.

(3) 胡渭在《禹贡雉指》中说: “積思久之竟不知䓠泽之塞为何故, 顷读后汉书而得之. 王景传云平帝之世 河、泣决坏未及得修, 泣渠东侵, 日月侵毁. 建武十年阳武令张汇上言: 河决积久, 日月侵毁, 济渠所漂数十许 县. 明帝纪永平十三年诏亦言, 自泣渠决败六十余岁, 加顷年以来雨水不时, 油渠东侵日月益甚, 水门故处皆 在河中, 漭瀁广溢莫测圻岸, 当时泣济之区河灾之羡溢为害如此. 济渠即䓠渎南去䓠泽不过二十余里, 则固 在所漂数十县之中者也, 河水汇滥必至其处, 历六十年而后已, 填淤之久, 空窦尽室, 地中伏流不能上涌, 䓠 泽之塞由于此”. 他认为这个䓠泽消失于东汉明帝年间.

(4) 岑仲勉在《黄河变迁史》中提到: “我对于䓠泽(假定系)消失的见解, 跟胡氏不同: 由于泽水本身的渗 漉性、蒸发性而干涸, 不尽由于河泥之填平; 可能在战国时期已经干涸, 故《汉书》地理志没有记载, 并不是存 在至东汉初年”。

\section{5 结语}

显然, 《禹贡》之后历史文献中记载了多个䓠泽. 但是, 正如本文对引文所作的分析, 大部分文献记述分 别存在以下几方面问题:一是原本指的就不是《禹贡》记述的塚泽, 如参考文献 $[10]$ 《左传》中记载的䓠泽; 二是这些记述脱离了《禹贡》对䓠泽 “济水……人于河, 溢为䓠” 产生原因与形成过程的描述, 而仅仅将䓠泽 看作是夏秋季节的洪水现象, 如参考文献 [13]、[15]; 三是这些文献对䓠泽的地理位置所做的论断, 并未以 六、七千年以前禹䓠泽形成时期的地质、地势和水文环境为依据, 不排除是根据明、清以来的自然地理环境 加以想象的结果, 如参考文献 [9]、[14]. 本文则以广泛收集、研究历史文献为基础, 第一次通过古自然地理 环境重塑来实现对禹䓠泽的考证和确认. 重塑的环境要素包括地质构造、地层分布、地貌形态和水文过程 等. 这种综合性的研究分析, 加上多个 ${ }^{14} \mathrm{C}$ 测年数据, 使本项研究成果具有充分的客观性和突破性进展.

正如本文引言所说, 现在作者所从事的调查研究的目的有两个:一是理清长久以来对《禹贡》所记载的 䓠泽的认识, 本文的论述已使禹䓠泽数千年前存在于䓠阳槽状洼地中得到了确认; 二是还需对禹䓠泽所产 生的湖相地层进行区域测量和更详细的测年工作, 搞清禹䓠泽分布范围及地理位置在数千年中的变迁, 以 便搞清它与不同时代文化遗址的关系, 这对禹䓠泽将会有一个更系统更全面的了解.

\section{6 参考文献}

[1] 阮 元(清). 十三经注疏-尚书禹贡. 北京: 中华书局编辑部, 1929:152.

[2 ] 刘钧枢. 郑州全新世地层初探. 地层学杂志, 1992,16(2):112-119.

[ 3 ] 河南省地质矿产局水文地质二队. 河南省郑州市区工程地质勘查报告. 河南省地质勘查研究院档案处, 1987:22.

[ 4 ] 河南省地质局区域地质测量队. 1：20 万郑州幅区域地质调查报告. 河南省地质勘查研究院档案处, 1989:66.

[ 5] 石建省,刘长礼. 黄河中下游主要环境地质问题研究. 北京: 中国大地出版社, 2007:153.

[6 ] 杨守敬,熊会贞. 水经注疏. 南京: 江苏古籍出版社, 1989:645.

[ 7 ] 陈万卿. 嘉靖䓠阳县志校注. 扬州:广陵书社,2006:147.

[ 8 ] 王 群,毛忠民. 河南省地图集. 北京: 中国地图出版社, 1997:23.

[ 9] 傅泽洪(清).行水金鉴. 北京: 商务印书馆,1936:581-605.

[10］阮 元(清).十三经注疏・春秋左传正义. 北京: 中华书局编辑部, 1929:1789.

[11] 胡 渭(清). 禹贡雉指. 上海: 上海古籍出版社,2006:卷十五三 四.

[12］陈隆文. 古䓠泽考. 陕西师范大学继续教育学报,2007, 24(3) :48-50.

[13] 杜省吾. 黄河历史述实. 郑州: 黄河水利出版社, 2008:25.

[14] 杨 钧. 先秦时期黄河下游之水初探. 见: 中国水利学会水利史研究会编. 黄河水利史论丛. 西安: 陕西科学技术出 版社 $1987: 27-38$.

[15］岑仲勉. 黄河变迁史. 北京: 中华书局,2004:193. 